UDK 785.6:786.2 Marić

\title{
DAS BYZANTINISCHE KONZERT FÜR KLAVIER UND ORCHESTER VON LJUBICA MARIĆ
}

$$
\text { Jelena Milojković-Djurić (Beograd) }
$$

Die eigenartige Verbundenheit des Alten und Neuen, die Verschmelzung der noch immer lebendigen musikalischen Tradition mit zeitgenössischen Musiksprache, kennzeichnet das Byzantinische Konzert für Klavier und Orchester, das zu den besten Werken der jugoslawischen Musik gezählt werden kann. Das serbische geistige Volkslied, das der Herkunft nach aus Byzanz übernommen wurde, diente als Inspiration und Ausgangspunkt dieses Werkes.

Das Byzantinische Konzert ist 1959 als ein Teil des Zyklusses »Musica Oktoicha entstanden. Zu diesem Zyklus gehörden: Musica Oktoicha No.1, das erwähnte Byzantinische Konzert für Klavier und Orchester, die Kammerkantate die »Schwelle des Traumes «, und Ostinato super Thema des Oktoichs für Streichquintet, Harfe und Klavier.

Die Komponistin Ljubica Marić hatte zuerst ihr Studium an der Musikschule in Belgrad, unter dem wohlbekannten Komponisten Josip Slavenski, begonnen. Auf Slavenskis Empfehlung setzte sie ihre musikalische Ausbildung in Prag fort und studierte 1929-1932 an dem staatlichen Musikkonservatorium in der Meisterklasse von Josef Suk. Wie sie sich selbst ausdrückte, war Josef Suk: »... ein richtiger Lehrer für mich, ... er fühlte, in welchem Masse er mir die Freiheit geben könnte, um zu arbeiten wie ich möchte, und um dann im richtigen Augenblick, wie einen goldenen Tropfen, seinen wertvollen Ratschlag zu geben, der mir so zu sagen gerade ins Blut ging. (Gespräch zwischen Ljuhica Marić und Miloš Jeftić im Rundfunk Belgrad, Zweites Programm, Dezember 1976.)

Nach dem Abschluss ihres Studiums bei Josef Suk studierte Ljubica Marić etwas später, 1936-1937, unter Alois Hába in der Abteilung für Vierteltonmusik am Prager Musikkonservatorium.

Während des Studiums in Prag interessierte sie sich leidenschaftlich für die neuesten Errungenschaften der musikalischen Kunst. Der Reichtum des Prager kulturellen Lebens der dreissiger Jahre war von grossem Wert für ihre künstlerische Entwicklung und Reife. Ljubica Marić hatte die Möglichkeit, die Werke der führenden Musikerpersönlichkeiten der Zeit kennenzulernen.

Ihre frühen Werke, die sie noch in Prag schrieb, führten sie in die Reihen der musikalischen Avantgarde ein. So wurde die Komposition Musik für Bläser, die Ljubica Marić 1931 komponiert hatte, auf dem Festival der Internationalen Gesellschaft für die zeitgenössische Musik in Amsterdam 1933 aufgeführt Im selben Jahr wurde auch ihre Musik für Orchester während der Musikalisch-Dramati- 
schen Arbeitstagung in Strassburg uraufgeführt unter der Leitung der Komponistin selbst. Ein drittes Werk, ihr Streichquartet, hat die Gesellschaft für die Moderne Musik in Prag gespielt. Die Aufführungen dieser Werke brachten der jungen Komponistin hohes Ansehen.

Nach der Rückkehr aus Prag setzte sie ihr weiteres Suchen nach dem autochtonen musikalischen Ausdruck fort. Mit der Zeit fühlte sie immer mehr die Verbundenheit mit dem heimatlichen Boden und die Wichtigkeit der Kenntniss der Herkunft, zu welcher sie sich hingezogen fühlte. Denn, wie sie sich selbst ausdrückt, der gegenwärtige Augenblick bezicht gleichzeitig die Vergangenheit und die Zukunft ein.

In diesem Suchen wurde für Ljubica Marić das serbische geistige Volkslied, das in der Sammlung Osmoglasnik (Oktoechos) enthalten ist, die Verkörperung »des unbegrenzten Raumes der heimatlichen Erde«. Osmoglasnik wurde von Stevan Stojanović-Mokranjac, einem der bedeutensten Komponisten der serbischen Musik um die Wende des 19. Jahrhunderts und den Anfang des 20. Jahrhunderts, gesammelt und aufgezeichnet, mit dem Wunsch den kirchlichen Gesang der hauptsächlich durch die mündliche Tradition überliefert wurde, von der weiteren Änderungen aufzubewahren.

Der serbische Osmoglasnik, ähnlich wie der Byzantinische Oktoechos enthält die kirchlichen Gesänge, Stichera idiomela, die nach dem System der acht Tonarten (griechisch Echos) angeordnet sind. Jeden Sonnabend werden die Stichera der Reihe nach, in aufeinanderfolgenden Tonarten gesungen. Der Text der Gesänge, welche zu dem Oktoechos gehören und die Auferstehung des Herrn feiern, Stichera Anastasima, bleibt für alle acht Tonarten unverändert.

Das Byzantinische Konzert ist nach den melodischen und kadenzierenden Formeln der zweiten, dritten und vierten Tonart komponiert. Die Komponistin betont das Gefühl der Mehrdeutigkeit und Mannigfaltigkeit des unerschöpften Reichtums der musikalischen Gedanken, die im Osmoglasnik verborgen liegen. Die Möglichkeit von verschiedenen rhythmischen Fassungen der charakteristischen melodischen Substanz gibt, laut Ljubica Marić, unter anderen, die notwendige kompositorische Freiheit in der Gestaltung des musikalischen Werkes. So wird der grundlegende Gedanke in dem Prozess zusammengefasst, umgewandelt und verdichtet, um in der neu gestaltenen Form die Bedeutung des Kernes zu erreichen, der die Bildung des ganzen musikalischen Satzes bedingt. Deswegen betrachtet Ljubica Marić die musikalische Form nicht als ein selbständiges Schema oder eine Schablone, da die Form aus dem eigentlichen musikalischen Inhalt hervorgeht.

Die Gestaltung der musikalischen Gedanken ist auch durch die aussergewöhnliche Orchestration des Werkes unterstrichen. Die Orchesterbesetzung umfasst ausser Streicher, 1 Harfe, 4 Hörner, 4 Trompeten, 3 Posaunen, 1 Tuba, das Schlagzeug mit Pauken, Triangel, Piatti, Gran Cassa und Tamtam. Der Klang wird nicht bloss wegen der koloristischen Qualitäten verwendet. Im ersten und dritten Satz des Konzertes wird die Kontrastierung und Abwechslung der Streichergruppe mit den Blechbläsern und wiederum mit dem Soloinstrument, die hauptsächlich freie, präludierende und rhapsodische Form geprägt.

Obwohl das Werk in der Form eines Konzertes geschrieben ist, bietet es keinen bravurosen Glanz für den Solisten. Es ist auch kein Werk, in dem das Klavier die Rolle des obligato Instrumentes spielt. Die Komponistin strebte nach 
einem Gleichgewicht der Stimmen und deren deutlichem Abhebung voneinander. In diesem Sinne stellt das Konzert einen Dialog oder eine Mitarbeit, dar.

Der erste Satz, Preludio quasi una Toccata, fängt mit durchsichtigen Klavierfloskeln, in Sechszehntel-Figuren, die dem präludierenden Charakter des Satzes entsprechen. Nach dieser kurzer Einleitung, wird der Hauptgedanke von der Trompete intoniert (T 6-21). Die breite, ruhige Melodie, die sich diatonisch, stufenweise entfaltet, wurzelt diastematisch in den charakteristischen melodischen und kadenzierenden Formeln der zweiten Tonart. Der typische Ambitus für die Stichera der zweiten Tonart ist in dem Hexachord: $f, g, a, b, c$, des enthalten, und prägt den charakteristischen Dur-Mollklang aus (grosse Terze und kleine Sexte). In dem Byzantinischen Konzert ist dieser Hexachord durch die dreifache Anknüpfung an die kreisförmige Tonalitätsdreieinigkeit F-Cis-A erweitert. Auf diese Weise schliesst die tonale Basis, in polytonalen Beziehungen alle zwölf Töne der chromatischen Leiter ein.

Beispiel 1

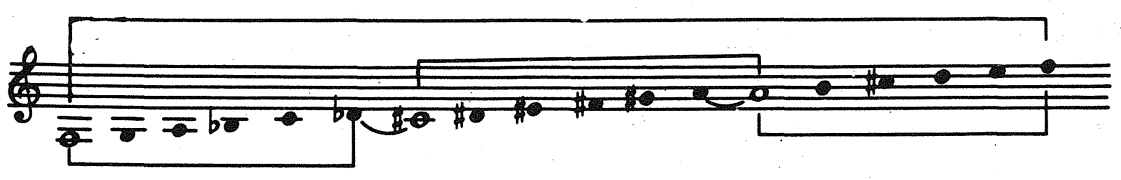

Jedoch die umgewandelte, polymetrische Struktur, die Verbindung von Zweiund Dreiteiligkeit und häufige Taktwechsel, hebt die anscheinende Verdichtung des musikalischen Ausdrucks hervor.

Beispiel 2 (Der Hauptgedanke des 1. Satzes)

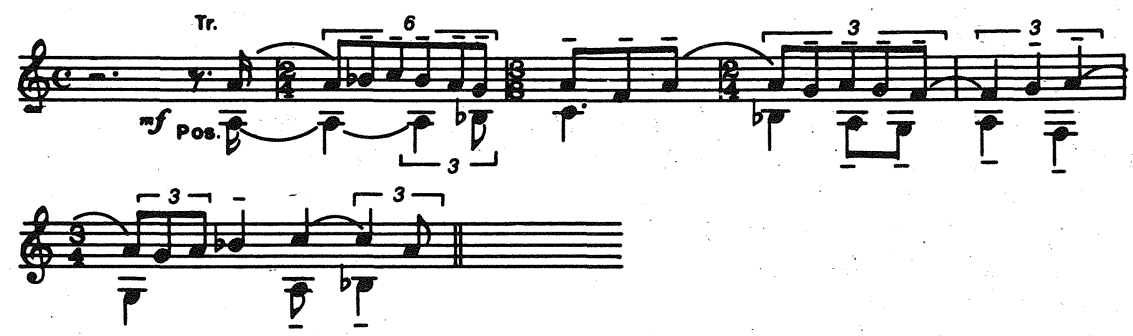

Beispiel 3 (Auferstehungssticheron der 2. Tonart)
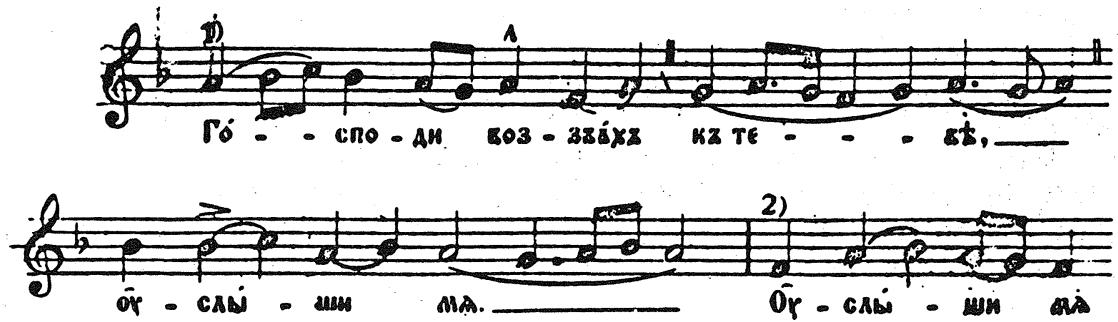

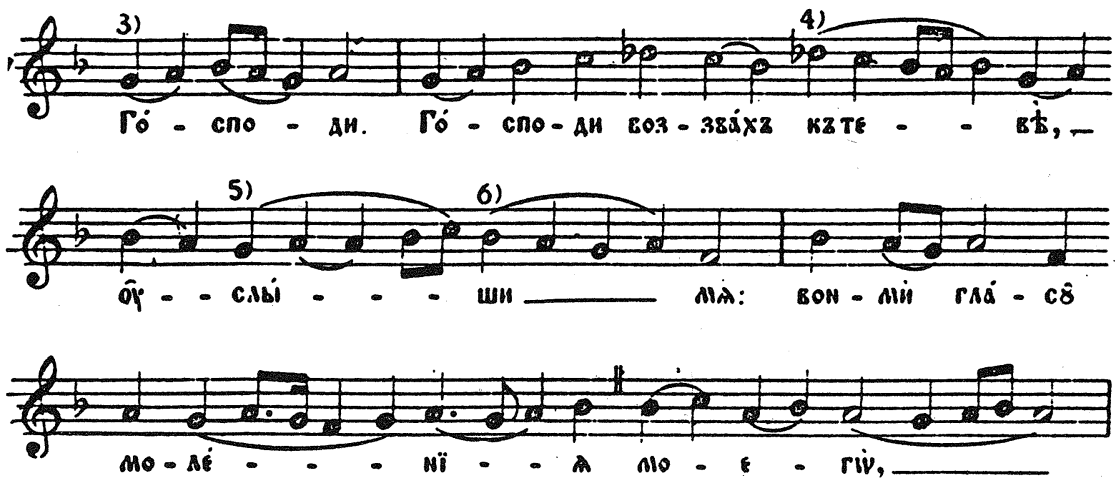

In der weiteren Entwicklung des ersten Satzes wird der Hauptgedanke durch die präludierenden Einwürfe des Solo-Instruments abgelöst, obwohl diastematische und rhytmische Elemente des Hauptgedankens in die musikalische Faktur eingesponnen sind. Damit werden auch die metrischen und harmonischen Auseinandersetzungen zwischen den verschiedenen Orchesterstimmen zum Vorschein gebracht.

Nach der Kadenz des Solo-Instrumentes folgt die zweite Erscheinung des Hauptgedankes, diesmal in den Streichern. In hoher durchdringender Lage, gespielt piano sul ponticello e senza vibrato, und nachgeahmt von der Trompete, stellt der Hauptgedanke diesmal den Ausdruck einer Vereinsamung und Hohlheit dar. Der Hauptgedanke kehrt noch einmal wieder, zwar metrisch und rhytmisch verändert, gespielt unisono von den Blechbläsern, unterstützt mit dem Pedal auf den Pauken. Immerhin setzt das Klavier das unruhige, ständig bewegte, wie ausgesponnene Spiel fort, das sich allmählich in eine Tokkate ausbildet. Der Satz endet in einer langsamen beruhigenden Bewegung.

Die Wiederholung der kadenzierenden Formel in immer verkürzter Form endet die Steigerung mit der mehrmaligen Wiederholung des Finalis $\mathrm{f}$, das wie beharrende Glocken unmittelbar zu dem Mittelsatz führt.

Der zweite Satz Aria ist durch die dominierende Rolle des Klaviers gekennzeichnet. Die filigranische Arabesken, die tragenden melodischen Töne umspielend, beziehen auch die chromatischen Töne ein, die aber nur figurativ verwendet werden. Alle Verziehrungen sind vollständig aufgeschrieben. Der musikalische Hauptgedanke des zweiten Satzes, von aussergewöhnlichen Schönheit und Anmut, ist mit der melodischen Substanz der dritten Tonart verwandt.

Beispiel 4 (Der Hauptgedanke des zweiten Satzes)

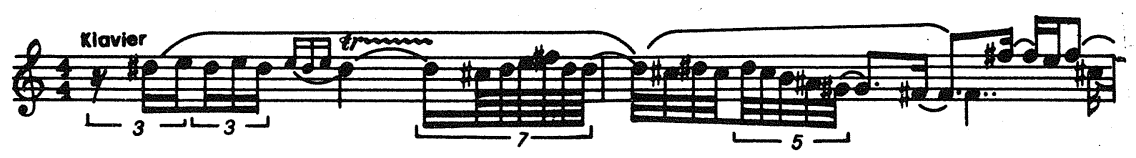




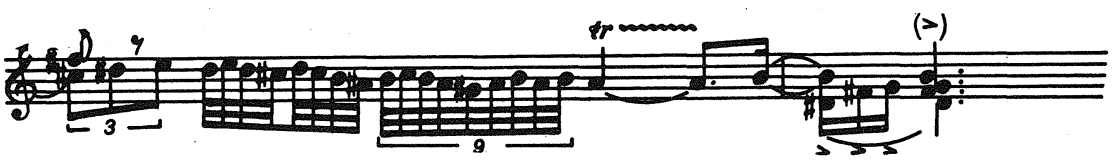

Das Orchester bringt kurze Einwürfe, die das anscheinend unendliche $\mathrm{Ge}$ webe des Solo-Instrumentes unterbrechen.

Der dritte Satz folgt ohne Unterbrechung, mit prägnanter Ostinatofigur der Pauken. Die tonale Grundlage des dritten Satzes resultiert hauptsächlich aus den melodischen Formeln der vierten Tonart.

Beispiel 5 (Die tonale Grundlage des 3. Satzes)

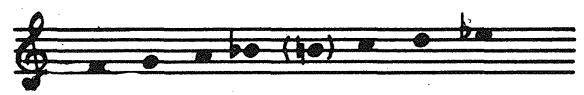

Nach der ostinaten Einleitung der Pauken folgt ein unruhiger und zerstückter Dialog zwischen Klavier und Orchester. Eine Abwechselung bringt das durchsichtige, lyrische Meno Mosso. Die Komponistin erklärte, dass sie in dieser Episode die Welt ihrer Kindheit zu evozieren versuchte: »... das Spielen der Kleinen, die wie die Grossen ausschauen möchten. « Klavier, unterstützt durch Harfe und Horn, bringt zuerst die in sich dreiteilige Episode vor. Der erste Teil (T 34-35) soll durch Erweiterung und Ausbau des staccato Motivs an die zerbrechliche Klangfärbung der Musik der Spieldose erinnern.

Der mittlere Teil (T 55-69) gespielt von der Trompete, hebt einen rhytmisch pointierten, tänzerischen Charakter hervor. Die etwas veränderte und erweiterte Wiederkehr des Anfangsteils (T 7.2-94) leitet zu der kanonischen Imitation des musikalischen Hauptgedankens des letzten Satzes über. Die Blechbläser exponieren feierlich die in Sekundstufen geführte Melodik, in gleichmässiger rhytmischer und metrischer Einteilung.

Beispiel 6 (Hauptgedanke des 3. Satzes)

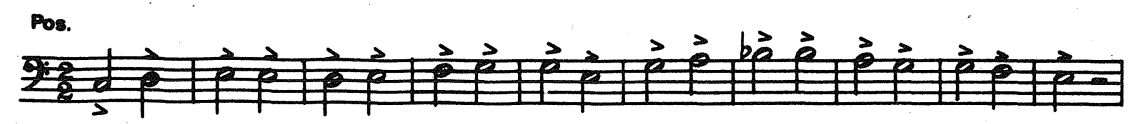

Beispiel 7 (Auferstehungs Stichera der 4. Tonart)
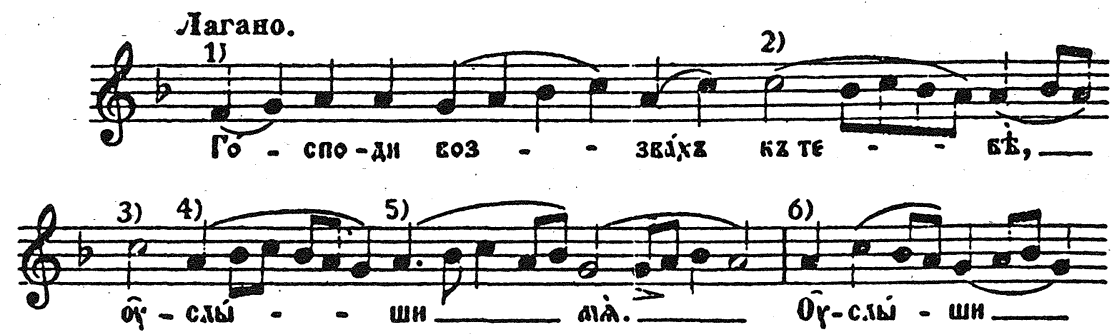

106 

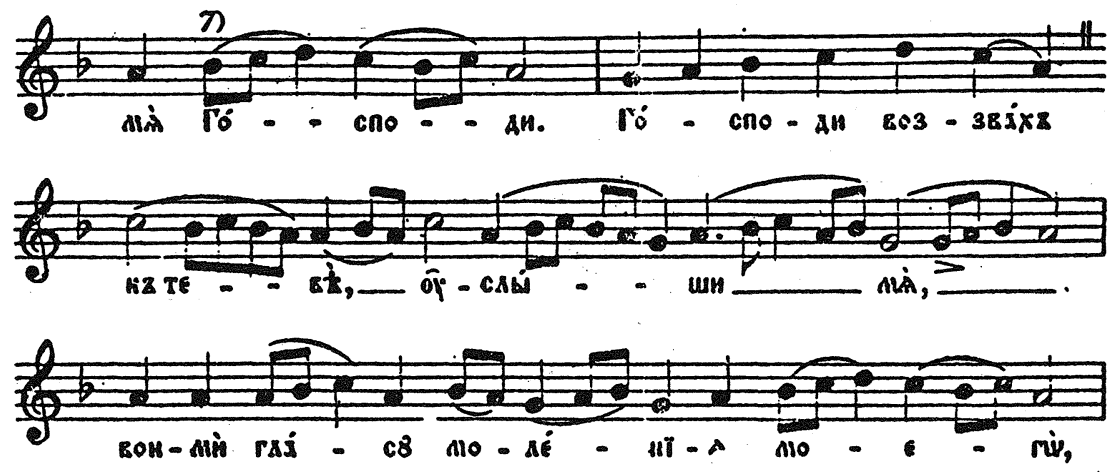

Die etwas veränderte Wiederholung des ersten Teiles des 3. Satzes wird durch die Pauken angemeldet; noch eine Reminiszenz an das poetische Meno Mosso, das zu einer neuen Steigerung führt. Der Satz endet nachdenklich, wie in einer neu enthaltenen Ruhe, begleitet, ähnliche wie der erste Satz, durch das fortdauernde Tönen der Finalis $\mathrm{f}$, das einem entfernten Geläut nahekommt.

Das Byzantinische Konzert wurde 1963 unter der Leitung von Oskar Danon uraufgeführt. Der solist war Jurica Muraj mit dem Orchester der Belgrader Philharmonie. Die Partitur des Werkes ist 1973 als eine Veröffentlichung der Serbischen Akademie der Wissenschaft und Künste in Belgrad erschienen.

\section{POVZETEK}

Bizantinski koncert za klavir in orkester Ljubice Marić, ki je nastal leta 1959 kot del cikla »Musica Oktoicha«, spada med najboljše stvaritve jugoslovanske glasbe. Označuje ga svojstveno povezovanje starega in novega ter spajanje še vedno žive glasbene tradicije s sodobno glasbeno govorico. Delo je inspirirala srbska duhovna ljudska pesem iz »Osmoglasnika «, ki predstavlja skladateljici $\mathrm{v}$ njenem iskanju avtohtonega izraza "neomejen prostor rodne zemlje«.

Bizantinski koncert je komponiran po melodičnih in kadenčnih obrazcih 2., 3. in 4. tonskega načina (glasa). Skladateljica poudarja občutje mnogoznačnosti in mnogoterosti neizčrpnega bogastva glasbene misli, ki jih obsega »Osmoglasnik«. Možnost različnega ritmičnega oblikovanja značilne melodične substance daje med drugim potrebno kompozicijsko svobodo $v$ gradnji dela. Tako je tudi osnovna misel $v$ razvojnem procesu kompozicije podvržena spreminjanju in zgostitvam in dobi pomen jedra, ki vpliva na formiranje celotnega glasbenega stavka. Zato Ljubica Marić ne vidi v muzikalni formi samostojne sheme ali šablone, kajti zanjo izhaja oblika iz same glasbene vsebine. Čeprav je delo napisano v obliki koncerta, ne nudi solistu bravuroznega sijaja. Seveda pa tudi ne gre za delo, v katerem bi imel klavir le vlogo obligatnega instrumenta. Avtorica je težila za ravnotežjem partov in njihovim razločnim diferenciranjem. $\mathrm{V}$ tem pogledu predstavlja koncert tudi dialog in pomembno soigro. 